\title{
O serviço social e a pandemia: reflexões prospetivas
}

The social work and the pandemic: prospective reflections

\section{Hermano Carmo ${ }^{1}$}

\begin{abstract}
Resumo
O objetivo deste texto é iniciar uma reflexão exploratória sobre as aprendizagens que colhemos da pandemia, eventualmente úteis na qualificação das práticas do serviço social.

Começar-se-á por descrever em traços gerais o impacto da pandemia na sociedade contemporânea, a três escalas de complexidade: micro, meso e macro. Seguidamente, far-se-ão algumas reflexões exploratórias sobre o papel do serviço social na pandemia, a partir de uma breve análise de documentos disponíveis e da observação indireta. Num terceiro momento, procurar-se-ão extrair algumas lições que permitam enfrentar coletivamente um futuro recheado de incertezas e de ameaças, mas também de oportunidades de superação.
\end{abstract}

Palavras-chave: pandemia Covid 19, cisne negro, nevoeiro informacional, responsabilidade social, prospetiva

\begin{abstract}
The aim of this text is to initiate an exploratory reflection on the lessons learnt from the pandemic, possibly useful in the qualification of social work practices.

We will begin by describing in general terms the impact of the pandemic on contemporary society, on three scales of complexity: micro, meso and macro. Next, some exploratory reflections will be made on the role of social work in the pandemic, based on a brief analysis of available documents and indirect observation. In a third moment, we will try to draw some lessons that allow us to collectively face a future full of uncertainties and threats, but also opportunities to overcome them.
\end{abstract}

Keywords: pandemic Covid 19, black swan, informational fog, social responsibility, foresight

\section{Introdução}

As reflexões que procurarei partilhar ao longo do texto que se segue, não são mais do que isso mesmo, meras reflexões exploratórias, sobre a multiplicidade de desafios que a intervenção social em geral e o serviço social em particular têm tido de enfrentar, face à pandemia de COVID 19. Como nos ensina a sociologia das revoluções, uma situação como esta, em que o Futuro entra abruptamente no Presente sem pedir licença (Toffler, 1970) com impactos profundos, não deixa ninguém como antes: ou deixa melhor, ou pior.

O título que escolhi, poderá parecer pretensioso, uma vez que a incerteza do presente é tal que, qualquer discurso sobre o futuro, pode ser olhado com suspeição e acusado de mera especulação fantasiosa. Apesar disso, arrisquei fazê-lo, justamente

\footnotetext{
${ }^{1}$ Professor Catedrático Jubilado da Universidade de Lisboa - ISCSP | E-mail: hermano@iscsp.ulisboa.pt
} 
porque em tempos de incerteza é importante refletir sobre os sinais portadores de futuro (Rösnay, 1977) para não entrar no futuro de marcha atrás (Peccei, 1981).

Atribui-se a Swami Vivekananda (1863-1902) a afirmação de que a verdadeira sabedoria passa por se ter consciência de que se sabe aquilo que se conhece e de que não se sabe o que se desconhece. É com esta consciência do pouco que sei sobre esta questão, que arriscarei a partilhar as reflexões que se seguem. Fá-lo-ei, numa postura de observador participante, procurando interpretar os dados que recolhi a partir do meu observatório particular (o meu papel de cidadão confinado, ainda que ligado em rede com muita gente e com o dever particular de ensinar estudantes do ensino superior), à luz do que tenho vindo a aprender ao longo do meu ciclo de vida.

Tenho consciência de que a tarefa é difícil, quer pelas minhas limitações pessoais, quer pelos constrangimentos externos. De entre estes, gostaria de salientar o nevoeiro informacional (Morin, 1991) que nos envolve, com uma sobreinformação que ameaça afogar qualquer observador, uma subinformação que aumenta a incerteza da análise e uma pseudoinformação que exponencia a desconfiança nos seus resultados.

Começarei por descrever em traços gerais o impacto da pandemia na sociedade contemporânea, a três escalas de complexidade: à escala micro (nas pessoas, individualmente consideradas e nas relações com os seus próximos; à escala meso (nas organizações e nas redes); e à escala macro (nas sociedades politicamente organizadas). Seguidamente, procurarei partilhar algumas reflexões sobre o papel do serviço social na pandemia para, num terceiro momento, procurar extrair algumas lições que nos permitam enfrentar coletivamente um futuro recheado de incertezas e de ameaças, mas também de oportunidades de superação. A este propósito, lembro-me sempre da sabedoria do Dalailama que afirmou, salvo erro, na sua autobiografia, que tudo na vida tem verso e reverso, proporcionando-nos um sofrimento inesperado no meio da alegria, mas também efeitos promissores de superação, de alegria e de Paz, em contextos de grande sofrimento.

\section{O impacto da pandemia}

Antes de mais, para falarmos da pandemia, vale a pena recordar em traços gerais, algumas caraterísticas dominantes da sociedade mundial e, em particular a portuguesa, no final de 2019, marcadas por três macrotendências: a aceleração da mudança, o agudizar das desigualdades e a fibrilhação dos sistemas de poder.

A sociedade mundial e a portuguesa no final de 2019 
Em termos globais, a primeira macrotendência estruturante a salientar foi a mudança acelerada (Toffler, 1970, 1980, 1991, 2006) que se registou a partir do terceiro quartel do século $\mathrm{XX}$, marcada por um processo heterocrónico de transitoriedade, novidade e diversidade, que, frequentemente, teve efeitos de anomia, de insegurança, de quebras na coesão social e de deterioração da orientação individual e coletiva (Fukuyama, 2000). Indicadores preocupantes deste caldo de cultura, foram o clima de nevoeiro informacional gerado, com efeitos no discernimento individual e coletivo, bem como a paradoxal incompetência para comunicar, designada por autismo social (Goleman, 2006) reduzindo a empatia, quer nas relações interpessoais quer nas relações coletivas.

Uma das caraterísticas associadas a esta mudança (simultaneamente causa e efeito dela), foi o peso cada vez maior das redes sobre as hierarquias coexistentes. Ora, como muito bem sugeriu um eminente historiador britânico dos nossos dias (Ferguson, 2018), enquanto que as hierarquias têm a vantagem de preservar a coesão e a estabilidade social, estimulando processos associativos diversos mas tendo o inconveniente de serem bastante resistentes à mudança, as redes apresentam um enorme potencial de transformação, porque estimulam a inovação, mas em contrapartida, corroem o controle social e põem em causa as referências instituídas, estimulando a emergência de tensões e processos dissociativos diversos (e.g. competições e conflitos).

A segunda macrotendência global estruturante, a desigualdade (Stiglitz, 2013, 2018; Piketty, 2020), desenvolveu-se a partir do início da década de oitenta, com a deterioração em cascata dos regimes de democracia popular, que culminou na queda do muro de Berlim e pôs fim à bipolarização existente desde o final da segunda guerra mundial.

Como sabemos, uma das caraterísticas doutrinárias da guerra fria, que opôs os regimes de democracia liberal aos regimes de democracia popular, foi que os primeiros sublinharam o valor da liberdade, enquanto os segundos o da igualdade. Com o fim da bipolarização, o pilar da igualdade foi claramente desvalorizado em detrimento da exaltação da conceção liberal de liberdade ${ }^{2}$.

\footnotetext{
${ }^{2} \mathrm{O}$ Ocidente e o mundo em geral haviam herdado da revolução francesa o tripé doutrinário estruturante, constituído pelos valores da liberdade, da igualdade e da fraternidade. O mundo bipolar do pós-guerra, exaltou os dois primeiros. Na sociedade política de então, o valor da fraternidade foi considerado do foro privado. Só a partir da última década do século $\mathrm{XX}$, com as políticas de terceira via protagonizadas pelos governos de Bill Clinton, Tony Blair e, entre nós, de António Guterres, a fraternidade passou a ser parcialmente considerada, pelo reconhecimento da solidariedade como instrumento de coesão social.
} 
A desigualdade, legitimada por uma ideologia dominante fundamentada em conceções darwinistas sociais $^{3}$ e num transpersonalismo financeiro ${ }^{4}$, teve um fortíssimo impacto na coesão social, fazendo aumentar o clima de tensão em virtude do ressentimento e revolta dos estratos mais pobres e excluídos e mais tarde, também, das classes médias, também elas afetadas no seu poder de compra.

A terceira macrotendência estruturante foi a profunda alteração do sistema de poderes, quer à escala macro (e.g. processo de descolonização, emergência do sistema das nações unidas) quer meso (e.g. cisões regionalistas, crise do modelo organizacional burocrático), quer micro (e.g. crise da família nuclear).

Se a desigualdade havia tido um impacto significativo na coesão social, a alteração e a complexificação dos sistemas de $\operatorname{poder}^{5}$ tiveram efeitos profundos na função orientação (desde as lideranças políticas às familiares), agudizando o clima de incerteza, medo e desconfiança, e fazendo baixar perigosamente os níveis de capital social.

Foi neste ambiente social que floresceu a crise financeira mundial do final da primeira década do presente século, com os danos diretos e colaterais conhecidos, que durou cerca de uma década a ser parcialmente ultrapassada ${ }^{6}$. Foi neste contexto, de retoma débil numa sociedade frágil, que emergiu a pandemia de COVID 19.

No final de 2019, a sociedade portuguesa, como sociedade aberta, era marcada pelo referido contexto estrutural, resultando numa conjuntura histórica particular, da qual se pode destacar:

- uma situação económica frágil, mas em fase de retoma, após alguns anos de crise financeira grave;

-uma arquitetura de Estado Social com bons indicadores de progresso ${ }^{7}$, tanto no campo da saúde como nos da educação e da proteção social, assente nos pilares do Serviço Nacional de Saúde, da rede pública de instituições educativas e da Segurança Social.

\footnotetext{
${ }^{3} \mathrm{O}$ darwinismo social, baseia-se numa leitura incompleta da teoria da evolução de Darwin, ignorando que este autor escreveu que as espécies evoluíram através de um processo não apenas dissociativo, por competição e conflito, mas também associativo, por cooperação e interajuda (Johnson, 2010).

${ }^{4} \mathrm{O}$ transpersonalismo financeiro resulta de um quadro axiológico deformado que elege o dinheiro como novo ídolo, bezerro de ouro, na expressão de Carl Strenger (Strenger, 2010).

${ }^{5}$ Traduzida no aumento dos decisores e das escalas em presença, e na crise de legitimação que se lhe seguiu, fruto da relativização de valores em concorrência, decorrente da situação de anomia generalizada.

${ }^{6}$ Digo parcialmente, pois ainda que em 2019, se observasse uma retoma financeira, as 3 questões estruturais que lhe deram origem mantiveram-se, agudizando-se a tensão social em torno de lógicas geopolíticas hegemónicas e de algumas estratégias políticas marcadas por um populismo exclusor.

${ }^{7}$ Ainda que com grandes fragilidades, por efeito de desinvestimentos significativos em setores chave como os da saúde e da habitação social.
} 
-Uma sociedade civil com a coesão e a confiança em fase de retoma, liderada por uma parceria política estável.

-Excelentes indicadores de segurança e de paz social, com baixos índices de criminalidade e de conflitualidade social, de que resultou a explosão da procura turística em reconhecimento da comunidade internacional.

Em suma, pode afirmar-se que, no final do ano de 2019, a conjuntura em Portugal era marcada pelo otimismo, quer devido à retoma económica (e.g. pela primeira vez em muitos anos previa-se um superavit orçamental e uma dívida pública a desacelerar), quer ao reconhecimento da pacificação social liderada pelos agentes políticos.

\section{A novidade e o impacto do cisne negro}

Foi neste contexto que a pandemia da COVID 19 surgiu como um cisne negro ameaçador, gerando um clima global de incerteza e de medo. O termo cisne negro havia sido sugerido, há uns anos, por um professor do Instituto Politécnico da Universidade de Nova Iorque, Nassim Taleb, para designar um evento inesperado e de grande impacto social, caraterizado pela complexidade e pela incerteza e indutor de anomia (Taleb, 2016).

Usá-lo-ei ao longo do texto que se segue, para sublinhar o impacto súbito e profundo que a pandemia teve na vida de todos e de cada um, não deixando ninguém igual ao que era antes. Isto aplica-se também, naturalmente, às práticas profissionais e, por maioria de razão às profissões que prestam serviços e cuidados de proximidade como as ligadas à saúde, à educação e à intervenção social.

\section{Impacto da pandemia à escala micro}

O impacto individual foi marcado por sentimentos de surpresa e de medo. Mas para além disso, teve efeitos profundos na sua estrutura cognitiva e emocional. De acordo com a teoria das inteligências múltiplas de Gardner $(1995)^{8}$, pode afirmar-se que a pandemia teve um significativo impacto individual, tanto em relação às inteligências instrumentais como relativamente às inteligências-bússola.

\footnotetext{
${ }^{8}$ Gardner sugeriu na sua teoria das inteligências múltiplas que cada pessoa não tem apenas uma inteligência, mas diversas (que ele definiu operacionalmente como capacidades para resolver problemas), que se desenvolvem em cada ser humano de forma variada e a ritmos diferentes (heterocronia). Do meu ponto de vista, as 9 inteligências identificadas por Gardner (1995), podem ser agrupadas em dois conjuntos: 6 permitem adestrar-nos para raciocinar, comunicar e usar melhor os nossos sentidos (linguística, lógicomatemática, espacial, musical, cinestésica e ecológica); as 3 restantes orientam adequadamente o nosso comportamento, de acordo com certos critérios e guiados pela lógica e pela ética (intrapessoal, interpessoal e existencial). Às primeiras podemos chamar inteligências instrumentais. Às segundas, porque nos norteiam, inteligências bússola (Carmo, 2018).
} 
Com o confinamento exigido, as referências de tempo e de espaço foram alteradas, bem como o próprio controle do corpo, alterando rotinas, aumentando a perceção de ameaça e criando um stresse prolongado. Um fator de aceleração desse stresse foi, sem dúvida, a concentração descontrolada sobre a pandemia, por parte de alguns meios de comunicação social e das redes sociais, o que criou um enorme nevoeiro informacional, com uma sobreinformação inútil de más notícias repetidas à saciedade, uma subinformação paralela sobre práticas de superação da situação e uma catadupa de pseudoinformação de notícias falsas e alarmistas, que dificultaram o uso do discernimento e da reflexão crítica.

No campo do desenvolvimento pessoal, a pandemia agudizou os dilemas estratégicos de cada idade, identificados por Erik Erickson há várias décadas ${ }^{9}$, desenvolvendo comportamentos individuais mais autónomos, solidários e responsáveis (e.g. maior preocupação com o autocuidado e com o cuidado de familiares mais frágeis) ou, pelo contrário, cristalizando comportamentos mais dependentes, egocêntricos e irresponsáveis (e.g. comportamentos negligenciando a segurança do próprio e dos outros).

Em função das opções individuais no campo interpessoal e intragrupal da dinâmica familiar, laboral, ou em grupos forçados de trabalhadores migrantes, observou-se o acentuar de processos associativos (e.g. maior colaboração e solidariedade), ou, pelo contrário, de práticas dissociativas (e.g. competição e conflito, propiciadores de stress e de burnout), não deixando ninguém como antes (Carmo, 2020).

\section{Impacto nas organizações e nas redes (escala meso)}

À escala meso, gostaria de salientar dois setores profundamente afetados pela pandemia: o trabalho e a educação.

\footnotetext{
${ }^{9}$ Confiança versus desconfiança básica ( $1^{\mathrm{a}}$ infância: 0-2 anos); autonomia versus dúvida ou vergonha ( $2^{\mathrm{a}}$ infância: 2-4 anos); iniciativa versus culpa (4-7 anos); operacionalidade versus inferioridade (7-12 anos); identidade versus auto difusão (adolescência); intimidade/distanciamento versus auto absorção (jovens adultos); geratividade versus estagnação (adultos); integridade versus desespero (idade madura). Nesta crise pandémica, foram significativos os efeitos no desenvolvimento pessoal quer em termos cognitivos quer emocionais, por vezes com sequelas na saúde física e mental (e.g. crianças que deixaram de ir à escola e de interagir com os pares; pessoas com doenças crónicas que deixaram de ter o necessário acompanhamento médico; aumento das taxas de morbilidade e de mortalidade não Covid, bem como das situações de isolamento, de depressões e de degradação da saúde mental em geral) (Carmo, 2020).
} 
No setor do trabalho, observou-se em geral a redução de rendimentos e de receitas, o aumento do subemprego e do desemprego, a falência de muitas empresas, e o aumento significativo dos índices de pobreza. Paralelamente a estas situações, no entanto, registouse a expansão de novos negócios e de novos produtos (e.g. comércio eletrónico, serviços ao domicílio, produção de materiais de higiene e segurança). O teletrabalho quando o conteúdo funcional o permitia, deixou de ser considerado uma atividade excêntrica e ameaçadora para a eficiência das organizações, passando a ser permitido ou mesmo obrigatório, condicionando profundas alterações no desempenho quer dos trabalhadores quer dos empregadores. O seu preço em termos sociais foi frequentemente elevado, dadas as muitas dificuldades que se registaram em muitas famílias de conciliar tempo (e o espaço) de trabalho com o tempo (e o espaço) para a família, principalmente no período em que as crianças tiveram de ficar em casa.

No setor da educação, os efeitos foram profundos, afetando todos os níveis de ensino. O principal foi, sem dúvida, a adoção do ensino a distância (sob a forma exclusiva ou mista), usando-se os vários suportes disponíveis (escrito, audiovisual e digital), adotando-se uma multiplicidade de equipamentos e canais (e.g. correio, computador, tablet, telemóvel) por vezes com grandes dificuldades técnicas (e.g. falta de equipamentos de base, dificuldades de acesso à Internet, etc.), com implicações negativas nos processos de aprendizagem.

\section{Impacto na sociedade politicamente organizada (escala macro)}

Finalmente à escala macro, os efeitos da pandemia foram gigantescos, como sabemos, tanto à escala ambiental (e.g. efeitos positivos da redução drástica das emissões de dióxido de carbono para a atmosfera, em virtude da redução da atividade produtiva e dos transportes; e efeitos negativos da produção de resíduos tóxicos, como máscaras usadas e de plásticos), como nas comunidades de vizinhança, na economia, na organização social em geral, nas políticas públicas e nos serviços e cuidados de proximidade.

No que respeita à governação, a pandemia constituiu um gigantesco tsunami que abalou o sistema político, quer quanto à sua função de coesão social quer quanto à de orientação coletiva:

-Relativamente à função de coesão, manteve o diálogo entre órgãos de soberania e entre governo e principal partido da oposição em decisões difíceis como as referentes ao estado de emergência, ainda que se registasse um crescimento de forças populistas nas eleições presidenciais, contra as tendências registadas no 
panorama internacional ${ }^{10}$. Por outro lado, revelou a importância do exercício do poder em detrimento da sua captura (eleições).

-Quanto à função orientação coletiva: as caraterísticas de cisne negro da pandemia, nomeadamente a incerteza, o inesperado e a urgência das decisões (dado o impacto profundo de eventuais não-decisões), bem como o contexto de subinformação, obrigaram frequentemente os governantes a tomar decisões de curto prazo e a corrigi-las frequentemente, dada a multiplicidade de variáveis em jogo e as recomendações contraditórias dos especialistas ${ }^{11}$.

Isto deu origem a frequentes críticas que, por via de regra, menosprezaram duas lições que a análise dos cisnes negros nos deu:

1. que em situações que configuram problemas complexos (Marques, $2017)^{12}$. o planeamento (pré-regulação) não pode ser linear, mas deve ser flutuante, isto é, acompanhado de escrutínio e correção permanente (co-regulação);

2. que a responsabilidade pela governação, num sistema político, não se circunscreve ao governo, mas também à oposição. E, numa crise desta natureza a responsabilidade de a superar é repartida entre governantes e governados. Ou seja, sem responsabilidade individual, não é possível fazer face à situação pois as orientações exigem consentimento para serem eficazes.

Em resumo, pode afirmar-se que a pandemia revelou, como uma lente de aumento, as fragilidades e contradições da sociedade contemporânea, já de si estruturada por uma mudança pouco controlada, por uma desigualdade crescente e a por uma fibrilhação dos sistemas de poder, de que resultou uma conjuntura anómica, caraterizada pela incerteza de um nevoeiro informacional, por um relativismo de valores ${ }^{13}$ e por uma ideologia hegemónica marcada pelo darwinismo social e pelo transpersonalismo financeiro. Os

\footnotetext{
${ }^{10}$ Em países com governação populista, como os Estados Unidos e o Brasil, o crescimento exponencial da pandemia evidenciado pelo $\mathrm{n}^{\circ}$ de pessoas infetadas, internadas e mortas desmentiu categoricamente os governantes e as correntes negacionistas, sendo responsável pela queda de Trump e pela perda de popularidade de Bolsonaro. Nas eleições presidenciais em Portugal, o candidato populista doméstico obteve, pelo contrário, o terceiro lugar, levando alguns analistas a afirmar que as forças populistas continuavam a crescer. Outros, porém, consideraram esses resultados como fenómeno isolado, dado o carisma pessoal do candidato, não replicável nas próximas eleições autárquicas e legislativas.

${ }^{11}$ Convém assinalar que, desde o início da crise, os especialistas chamados a ajudar a preparar as políticas públicas foram na sua generalidade, do campo da saúde e da economia, registando-se um silêncio ruidoso relativamente aos especialistas de outras áreas (e.g. intervenção social, ensino a distância).

12 Problemas complexos (wicked problems), são problemas em que, dado número de variáveis, de protagonistas e de relações em jogo, não existe consenso, quer quanto à sua resolução, quer mesmo quanto à sua equação (Marques, 2017).

${ }^{13}$ Sobre a questão do relativismo de valores veja-se, por exemplo, Bauman, Z. (2016) e Francisco (2020). Bauman chamou-lhe cegueira moral.
} 
seus efeitos individuais e coletivos, traduziram-se em danos, não só na saúde física e mental de pessoas e de coletivos, mas também em tensão social, em travagem da economia, ainda convalescente de uma grave crise financeira, e em tensão política, quer em matéria de coesão social, quer de orientação coletiva.

A par dos efeitos negativos referidos, é importante salientar que a pandemia também permitiu o surgimento de um conjunto significativo de boas práticas que ajudaram a enfrentar a crise e a procurar superá-la (e.g. utilização inovadora das TICs, cooperação internacional na busca de vacinas, cooperação europeia em matéria de políticas públicas de saúde, de economia e de proteção social).

Por outro lado, permitiu criar um melhor discernimento sobre a realidade, assente em evidências científicas e uma participação social mais esclarecida e não em pseudoinformações alienantes, possibilitou um maior debate sobre os valores orientadores das decisões, desmascarando forças populistas e autoritárias e obrigou a um maior escrutínio sobre as práticas individuais e coletivas, constrangendo-as a pautar-se por critérios de maior responsabilidade social.

A situação que acabo de descrever, serve de contexto para refletir, seguidamente, sobre o papel do serviço social na pandemia

\section{O serviço social e a pandemia}

Quase desde o início da primeira vaga, diversas organizações e profissionais de serviço social começaram a publicitar as suas reflexões sobre a crise pandémica e sobre o modo de intervirem. A este propósito, vejamos brevemente alguns documentos divulgados em reação ao primeiro surto.

\section{Um olhar rápido sobre as raízes do Presente do serviço social}

Por práticas profissionais pós-modernas entendam-se todas aquelas que são desenvolvidas tendo por referência a recriação do conceito de necessidade social e de bem-estar, (...) como finalidade a autonomização das pessoas relativamente às instituições sociais, (...). O seu objetivo prioritário está associado a uma cultura de cidadania. (Mouro, 2014, p.55).

Perante o agravamento da crise (...), os assistentes sociais seguem caminhos diferenciados: podem tentar fugir ao confronto direto com as populações, refugiando-se no trabalho burocrático-administrativo; podem refugiar-se no 
cumprimento estrito da legislação sempre em alteração, como se fossem meros aplicadores da lei, sem assumirem uma postura crítica e interrogadora sobre a legitimidade das leis; podem assumir no trabalho direto com indivíduos e grupos, a ação dialógica para (co)construir a consciência política das populações para a ação contra a pobreza e as desigualdades. (Granja, 2014, p. 80).

As citações chamam para a necessidade atual de uma ação profissional marcada pela autonomização dos sistemas-clientes e para os efeitos perversos de algumas práticas que põem em risco esse desígnio.

Desde as suas origens que a prática do Serviço Social assentou em dois pilares: o primeiro, mais preocupado em ajudar os sistemas-clientes a ultrapassar estados de carência, procurando responder a necessidades de sobrevivência e de segurança; o segundo, em assumir-se como recurso, para os ajudar a autonomizar-se, a ganhar o poder suficiente para se tornarem sujeitos da sua própria história (Freire, 1972; Falcão, 1979). Daqui resultou, ao longo da sua história já mais que centenária, uma prática profissional com três dimensões (assistencial, socioeducativa e sociopolítica) diferentemente acentuadas. Sabendo nós que as três dimensões são indispensáveis a um bom desempenho, reconhece-se que, em diferentes momentos históricos, a profissão foi ideologicamente contagiada, daí resultando práticas incorretas com evidentes danos perversos $^{14}$.

\section{Visita a alguns documentos produzidos nos primeiros meses}

Após o choque e a surpresa iniciais, a pandemia, suscitou uma reação quase imediata por parte de diversas organizações ligadas à intervenção social em geral e ao serviço social em particular, que publicaram alguns documentos orientadores, como os sintetizados no quadro $\mathrm{n}^{\circ} 1^{15}$, sobre o qual gostaria de sublinhar as seguintes ideias-chave:

\footnotetext{
${ }^{14}$ São conhecidos os excessos seguidistas em relação a forças conservadoras dominantes, denunciados pelo movimento da reconceptualização dos anos sessenta do século passado. Menos falados, foram também as práticas voluntaristas de alguns agentes desse mesmo movimento transformando por vezes o (a) profissional em mero (a) comissário (a) político (a) (Ander-Egg, 1984). Sobre a situação portuguesa e nomeadamente acerca da sobrevalorização da perspetiva assistencial em detrimento da socioeducativa e da sociopolítica, veja-se, por exemplo: Pinto (2012) e Esgaio (2018).

15 Este quadro é meramente exploratório, não tendo pretensões de representatividade, tendo apenas um intuito ilustrativo de algumas das perceções e das preocupações dos respetivos coletivos que os produziram. O conjunto integra 7 documentos, publicitados entre março e agosto de 2020, na primeira vaga da pandemia, 3 deles de coletivos estrangeiros e 4 de origem nacional.
} 
Quadro n. ${ }^{\circ}$. Síntese das ideias chave de alguns documentos orientadores

\begin{tabular}{|c|c|c|c|}
\hline Data & Autoria & Título & Ideias chave \\
\hline $23 / 3$ & $\begin{array}{l}\text { Grupo de } \\
\text { serviço social } \\
\text { da APCP, da } \\
\text { Comissão } \\
\text { Nacional de } \\
\text { Cuidados } \\
\text { Paliativos }\end{array}$ & $\begin{array}{l}\text { Boas Práticas do } \\
\text { Assistente Social } \\
\text { COVID-19 }\end{array}$ & $\begin{array}{l}\text { - Os (as) assistentes sociais estão na linha da } \\
\text { frente } \\
\text { - Falta de informação, escassez de recursos, } \\
\text { isolamento social e ansiedade. } \\
\text { - Papel do Serviço Social na } 1^{\mathrm{a}} \text { vaga } \\
\text { pandémica. } \\
\text { - Papel do Serviço Social no período pós- } \\
\text { pandémico. }\end{array}$ \\
\hline Julho & $\begin{array}{l}\text { Centro Lusíada } \\
\text { de Investigação } \\
\text { em Serviço } \\
\text { Social e } \\
\text { Intervenção } \\
\text { Social } \\
\text { (CLISSIS) }\end{array}$ & $\begin{array}{l}\text { Desafios ao serviço } \\
\text { social no contexto } \\
\text { da COVID-19 }\end{array}$ & $\begin{array}{l}\text { - Dificuldades prévias dos cidadãos, } \\
\text { agravadas pela pandemia } \\
\text { - Exemplos de práticas de intervenção a } \\
\text { melhorar em matéria de comunicação. } \\
\text { - Necessidade de qualificar o processo de } \\
\text { ajuda }\end{array}$ \\
\hline Abril & $\begin{array}{l}\text { Grupo Estatal } \\
\text { de Intervención } \\
\text { en Emergencias } \\
\text { Sociales, do } \\
\text { Consejo } \\
\text { General del } \\
\text { Trabajo Social }\end{array}$ & $\begin{array}{l}\text { Recomendaciones } \\
\text { del Consejo } \\
\text { General del } \\
\text { Trabajo Social para } \\
\text { los Sevicios } \\
\text { Sociales ante-la } \\
\text { situación del } \\
\text { COVID } 19 \text { y la } \\
\text { post crisis }\end{array}$ & $\begin{array}{l}\text { - Funções do sistema público de cuidados } \\
\text { primários. } \\
\text { • Recomendações gerais aos Servicios } \\
\text { Sociales de Atención Primaria (serviços de } \\
\text { proximidade. } \\
\text { - Reformas necessárias nos sistemas de } \\
\text { política social. } \\
\text { - Recomendações específicas às e aos } \\
\text { profissionais dos serviços sociais }\end{array}$ \\
\hline Abril & $\begin{array}{l}\text { Grupo Estatal } \\
\text { de Intervención } \\
\text { en Emergencias } \\
\text { Sociales, do } \\
\text { Consejo } \\
\text { General del } \\
\text { Trabajo Social }\end{array}$ & $\begin{array}{l}\text { El duelo por el } \\
\text { COVID } 19 \text { desde el } \\
\text { Trabajo Social }\end{array}$ & $\begin{array}{l}\text { - Os (as) AS são também cidadãos, atingidos } \\
\text { pela pandemia. } \\
\text { - A crise requer um esforço adicional de } \\
\text { autorregulação e de prevenção da insularização } \\
\text { profissional, nomeadamente os (as) estão na } 1^{a} \\
\text { linha de intervenção (e.g. em lares de idosos e } \\
\text { em hospitais). }\end{array}$ \\
\hline s.d. & $\begin{array}{l}\text { Paul, Brun \& } \\
\text { Taylor (2020) }\end{array}$ & $\begin{array}{l}\text { Recasting social } \\
\text { workers as } \\
\text { frontline in a } \\
\text { socially } \\
\text { accountable } \\
\text { COVID-19 } \\
\text { response }\end{array}$ & $\begin{array}{l}\text { - o Serviço Social é uma profissão da linha } \\
\text { da frente, todavia não suficientemente visível, } \\
\text { devido ao modelo de intervenção hegemónico, } \\
\text { que tende a sobrevalorizar as profissões ligadas } \\
\text { aos cuidados de saúde diferenciados. }\end{array}$ \\
\hline Julho & $\begin{array}{l}\text { Secretariado } \\
\text { Executivo da } \\
\text { Comissão } \\
\text { Nacional para } \\
\text { os Direitos } \\
\text { Humanos }\end{array}$ & $\begin{array}{l}\text { Portugal e a } \\
\text { promoção e } \\
\text { proteção dos } \\
\text { direitos humanos } \\
\text { em tempos da } \\
\text { pandemia da } \\
\text { COVID19 }\end{array}$ & $\begin{array}{l}\text { - Medidas tomadas e a tomar em diversos } \\
\text { setores, de salvaguarda dos Direitos Humanos }\end{array}$ \\
\hline agosto & $\begin{array}{l}\text { Conselho } \\
\text { económico e } \\
\text { social }\end{array}$ & $\begin{array}{l}\text { Sair da crise: } \\
\text { emprego, apoios } \\
\text { sociais e saúde }\end{array}$ & $\begin{array}{l}\text { - } \quad \text { Respostas do SNS e de apoio social e } \\
\text { económico dos setores público privado e } \\
\text { terceiro setor } \\
\text { - Necessidade de escrutínio das medidas } \\
\text { tomadas } \\
\text { - Papel dos parceiros sociais } \\
\text { - A questão do aproveitamento político da } \\
\text { pandemia }\end{array}$ \\
\hline
\end{tabular}


i) Sobre a crise em geral:

-Existência de fragilidades prévias dos cidadãos, agravadas pela pandemia.

-Os principais problemas registados pelos (as) assistentes sociais foram falta de informação e a escassez de recursos, bem como o isolamento social e a ansiedade dos sistemas-clientes quer dos interventores.

ii) Sobre o processo de intervenção durante a $1^{\text {a }}$ vaga:

-Necessidade de combinar a intervenção presencial com a intervenção a distância, tirando partido das TICs.

-Necessidade de desburocratizar, desmaterializar, equipar e reforçar o financiamento dos sistemas de proteção social e de agilizar a comunicação, quer no apoio direto quer no trabalho em parceria, mantendo as garantias de proteção de dados.

-Necessidade de qualificar o processo de ajuda, reforçando a humanização dos serviços, garantindo o princípio da autodeterminação das pessoas e das famílias -Listagem de medidas tomadas (e a tomar) em diversos setores, de salvaguarda dos Direitos Humanos (e.g. saúde, informação, educação, habitação, cultura, grupos vulneráveis, mercado de trabalho, setor público, setor social, desporto, justiça, segurança defesa nacional, igualdade de género, portugueses no estrangeiro e cooperação internacional

iii) Sobre os (as) assistentes sociais em particular:

-Durante $1^{\text {a }}$ vaga da pandemia, estiveram envolvidos (as) no acompanhamento das altas hospitalares, no apoio domiciliário à alimentação à medicação, no acompanhamento do impacto social e emocional nas situações de isolamento familiar e de morte por COVID19 e na ajuda aos profissionais de saúde em situação de maior vulnerabilidade.

-Situaram-se objetivamente na linha da frente de combate à pandemia, ainda que tal fosse normalmente omitido na comunicação social. Um dos documentos (Paul, Brun \& Taylor, 2020) interpreta a omissão, referindo-se ao paradigma de intervenção dominante que apenas valoriza a intervenção sanitária ${ }^{16}$.

\footnotetext{
${ }^{16}$ De maio a julho de 2020 desenvolveu-se um projeto de investigação sobre os efeitos da pandemia na saúde mental (VVAA, 2020). Só em 21 de outubro foi divulgado o respetivo relatório, com 5 medidas de curto prazo, 4 de médio prazo e 5 de longo prazo. Provavelmente, este facto reforce a explicação para a atrás referida pouca visibilidade do serviço social na $1^{\text {a }}$ vaga da pandemia, a qual é talvez mais evidente na prevenção primária e secundária da saúde mental.
} 
-Recomendação de uma atitude de grande disponibilidade face à situação e de abertura de canais alternativos com a população mais vulnerável (e.g. teleassistência) e o acompanhamento continuado de casos mais graves.

-Recomendação de comportamentos de autocuidado, com boas práticas de segurança, dada a sua condição de profissionais em risco.

-Assunção de que, no período pós-pandemia, serão agentes indispensáveis para a reconstrução familiar, laboral e económica e na implementação de novas políticas sociais.

Em termos analíticos é tão importante o discurso dito como o omitido. Neste sentido, vale a pena referir três omissões importantes, nomeadamente quanto aos serviços e cuidados de proximidade em matéria de ação social, à questão da saúde mental e ao não reconhecimento da população mais velha como parceira social (a qual, aparentemente, não teve direito a voz durante a $1^{\mathrm{a}}$ vaga).

\section{Papel da(o) assistente social na pandemia}

Conforme se pode observar nos documentos atrás referidos, os desafios e as preocupações evidenciados face à pandemia integram os dois objetivos omnipresentes: por um lado, ajudar as pessoas e os coletivos a sair da situação de carência em que ficaram ou que foi agravada pela crise: por outro lado, assumir-se como recurso para a sua autonomização como cidadãos responsáveis. E, em qualquer dos casos, tendo em conta a fragilidade pessoal do (a) próprio (a) profissional.

O papel da e do profissional em Serviço Social em situações de ameaça à proteção civil é já reconhecido há vários anos. Dada a complexidade destas situações, é-lhe exigido que atue com o máximo de eficácia e de eficiência ${ }^{17}$ num curto espaço de tempo, no sentido de tornar possível.

- caracterizar a situação-problema nas suas linhas mestras, distinguindo os problemas que requerem ação imediata dos que, sendo importantes, exigem uma resposta diferida.

- desenhar um plano de intervenção com resultados a atingir de imediato, a curto e a médio prazo;

\footnotetext{
17 No sentido de atingir os objetivos determinados (eficácia) com a melhor combinação de meios
} (eficiência), nomeadamente o tempo (que é aqui um meio indispensável), os meios humanos e materiais 
-identificar, mobilizar e organizar os recursos necessários à intervenção (Carmo, 1999, p.226).

Para atingir tais metas, é fundamental que disponha, em termos pessoais, de um bom arcaboiço cognitivo e emocional, de modo a assumir-se como parte da solução e não como mais um elemento do problema ${ }^{18}$.

A crise sanitária pôs em evidência as quatro condições indispensáveis a uma intervenção social eficaz e eficiente: o conhecimento dos principais elementos que traçam o quadro de ameaças e de oportunidades do ambiente de intervenção; o conhecimento da cultura do sistema-cliente; o autoconhecimento, a fim de tirar partido do seu potencial e limites pessoais; e o controle dos meios de comunicação, próprios e alheios, presenciais e a distância, disponíveis para uma intervenção adequada (Carmo, 1999, p.41). Vejamos como cada uma dessas condições foi afetada.

\section{A crise e o ambiente de intervenção}

Dada a natureza de cisne negro da pandemia (novidade e impacto), o ambiente social foi marcado, antes de mais, pela incerteza. Isto fez com que os especialistas titubeassem diagnósticos e recomendações divergentes, os decisores políticos navegassem à vista, as oposições criticassem a falta de planeamento, ignorando que as duas caraterísticas de qualquer problema complexo são, justamente, as incertezas quanto à sua equação e quanto às suas soluções, e os cidadãos comuns interiorizassem na pele o que é uma situação de anomia.

Em tal vaga de incerteza, o serviço social, na sua condição de profissão que executa políticas públicas e presta serviços e cuidados de proximidade ${ }^{19}$, desenvolveu o seu trabalho em condições muito difíceis, uma vez que não dispunha de informação suficientemente validada pelos diversos observatórios, muito menos a tinha em matéria de boas práticas dada a novidade e complexidade da situação, não podendo contar com o subsistema laboratório social; e apenas dispondo de orientações políticas em permanente atualização, como referi atrás.

\footnotetext{
${ }^{18}$ Como referi atrás a propósito da teoria das inteligências múltiplas de Gardner (ver nota 7), é-lhe exigido que tire partido, tanto das suas inteligências instrumentais como das inteligências-bússola, desenvolvidas previamente através de uma formação que tenha valorizado ambas.

${ }^{19} \mathrm{Em}$ termos de análise sistémica, tenho sugerido que qualquer sistema de intervenção social integra 4 subsistemas: o de política social que decide e orienta; o de observatório social que estuda e diagnostica; o de laboratório social que experimenta novas soluções; e o de cuidados de proximidade que executa e presta serviços (Carmo, 2011, p.43).
} 


\section{A crise e conhecimento dos sistemas clientes}

Um outro aspeto que dificultou o trabalho foi o alargamento e complexificação do sistema-cliente. Com efeito, com o agravamento da pandemia, o número de pessoas e famílias a necessitarem de cuidados materiais e imateriais aumentou significativamente, e a sua composição estendeu-se a gente que nunca havia tido necessidade de recorrer a apoios sociais, a qual não estava preparada para a situação de dependência em que passou a ficar fazendo aumentar os sentimentos de medo e ansiedade e tendo efeitos demolidores na sua autoestima ${ }^{20}$.

Por outro lado, foi evidente o efeito multiplicador na desigualdade anteriormente existente, tanto na economia (da família e do tecido empresarial), como no capital humano, dado o diferente nível de instrução e literacia bem como as diferentes condições materiais em que viviam (e.g. habitações sobrelotadas e dificuldades de acesso à internet).

\section{A crise e o autoconhecimento}

Outra das surpresas com que este cisne negro confrontou muitos indivíduos foi a de, ao olhar para o espelho, não reconhecerem as pessoas que julgavam ser: se, para alguns, constituiu uma oportunidade para descobrir talentos escondidos e forças inesperadas, o que lhes permitiu ficar mais fortes e melhores, para muitos outros, após a surpresa veio a revelação de muitas fragilidades, causadoras de grande sofrimento.

Os (as) profissionais de serviço social não foram imunes a este processo. Só que, para além de pessoas comuns, com o dilema de se superarem ou sucumbirem, eram profissionais com uma responsabilidade profissional acrescida de ajudar os outros. E isso, muitas vezes, sem a rede de segurança de uma supervisão securizante (Ribeirinho, 2019).

\section{A crise e os meios de comunicação}

Referi atrás o ambiente de nevoeiro informacional que já existia antes e que cresceu com a pandemia, agravado pela irresponsabilidade de alguns meios de comunicação que se transformaram em tabloides e pela impunidade demencial de várias pessoas que usaram as redes sociais para projetarem fragilidades e sentimentos negativos (e.g. medo, preconceitos, inveja, ódio, racismo, xenofobia).

Estes factos, vieram evidenciar a necessidade de uma estratégia de educação para a cidadania generalizada, de modo a aumentar os níveis de autonomia, solidariedade e responsabilidade social da população (Carmo, 1999, 2014a). No campo específico da educação, a pandemia veio chamar a atenção para um recurso, com provas dadas há

\footnotetext{
${ }^{20}$ Foi uma reação semelhante à dos novos-pobres, registada nas crises económicas anteriores.
} 
muitas décadas, mas frequentemente encarado com desconfiança, muitas vezes fruto de preconceitos conservadores: a educação a distância ${ }^{21}$.

Apesar deste contexto adverso, as e os profissionais de serviço social, enfrentaramno com determinação, tanto no setor público, como no privado, como ainda no terceiro setor, desempenhando variados papéis (e.g. acolhimento e ajuda direta, direção de equipamentos infantojuvenis, de lares de idosos, de centros para imigrantes e para refugiados) (Cardoso, Vilar, \& Casquilho-Martins, 2020; Carvalho, 2020; Reigada, 2020). Estiveram presentes na linha da frente, em hospitais e nas comunidades, com a sua tecnicidade e com as suas limitações.

Uma coisa me parece certa: tem sido uma experiência inesquecível (de sofrimento e de superação) e uma fonte de ensinamentos. E, é nesse sentido, que gostaria de terminar a minha reflexão procurando extrair algumas lições que permitam encarar com mais confiança o futuro que, já percebemos, é incerto.

\section{Lições para um futuro incerto}

Há bem poucos anos, na abertura de uma obra coletiva sobre teorias e práticas de serviço social, as coordenadoras afirmavam:

é necessário um movimento de reflexão dual por um lado, a abertura multidisciplinar a outras áreas do saber e, por outro lado, a construção de um saber transdisciplinar específico do Serviço Social que possibilite a construção de uma identidade cognitiva, operativa e deontológica (Carvalho \& Pinto, 2014, p.23).

A preocupação expressa pelas autoras, era indispensável antes da pandemia e, como procurei mostrar atrás, torna-se um imperativo de sobrevivência, durante e após ela. A sua primeira lição é de que o serviço social só sobreviverá como profissão, se souber integrar outras áreas de saber e do fazer, sem coutadas, sem corporativismos, mas respeitando escrupulosamente o seu princípio doutrinário orientador que é o personalismo, o qual o compromete a pautar a sua atuação pela defesa da dignidade da pessoa humana. Ou seja, "a eficácia do serviço social (...), decorrerá inevitavelmente da convergência entre o que os seus profissionais souberem, disserem e fizerem, ou seja da autenticidade da profissão e da integridade dos profissionais" (Carmo, 2014b, p.126).

\footnotetext{
${ }^{21}$ Sobre a educação a distância, veja-se por exemplo Carmo (2010) e Carmo \& Carmo (2018).
} 
Ao refletir sobre que lições devemos extrair da pandemia para melhorar o desempenho do Serviço Social numa ótica de superação permanente, vêem-me à memória as duas palavras-chave do Concílio Vaticano II que, há já seis décadas, lhe permitiram adaptar-se ao mundo do século XX: refontalização e atualização. $\mathrm{O}$ primeiro, obrigou a um revisitar as fontes (naquele caso, a Sagrada Escritura e as práticas dos Padres da Igreja); o segundo, a um esforço profundo para ler os sinais dos tempos, ou seja, para diagnosticar a de forma atualizada a sociedade e procurar os sinais portadores de futuro. Aplicando esta recordação ao Serviço Social, diria que será necessário, respeitar e pôr a render o património acumulado de conhecimentos com mais de cem anos de prática, complementando-o com uma visão prospetiva. É esta última que interessa à presente reflexão, pois a questão, recordo, é saber que lições devemos extrair da vivência da pandemia para a prática do Serviço Social.

\section{Fontes para uma visão prospetiva}

Do meu ponto de vista, antes de mais será necessário construir um observatório adequado, recorrendo tanto a fontes científicas, como doutrinárias e políticas.

No que respeita aos contributos científicos, recordo apenas três: o de Hans Rösling (2019), especialista mundialmente reconhecido no campo da interpretação de dados, que sublinhava a urgência de vigiar permanentemente o modo como se interpretam os dados (sobretudo os especialistas), dado o enviesamento emocional, tendente a ver o mundo apenas pelo seu lado negativo ${ }^{22}$; o de Nassim Taleb (2016), professor da Universidade de Massachusetts em Amherst, professor de Ciências da Incerteza, que generalizou e aplicou o conceito de cisne negro, atrás utilizado; e o da corrente da abordagem sistémica, que constitui um instrumento poderoso para a análise de problemas complexos (Rosnay, 1977; Carmo, 2011; Marques, 2017) e para a definição de estratégias adequadas (flexíveis e de governação integrada) de intervenção.

Quanto às fontes doutrinárias, autênticas bússolas, constituídas por documentos e pessoas mundialmente reconhecidos e que integram referências consensuais sobre os caminhos a trilhar no sentido de construir uma sociedade mais resiliente e sustentável e com mais bem-estar para todos (Laurent, 2020), podem para já convocar-se as seguintes:

(O) tripé doutrinário da revolução francesa, assente nas ideias de liberdade, igualdade e fraternidade, embora as duas primeiras não sejam universalmente

\footnotetext{
22 Recomendo vivamente a qualquer assistente social, a leitura de Factfullness- Factualidade (Rosling \& Rosling, 2019), como propedêutica à análise social.
} 
valorizadas, a fraternidade parece ter consenso universal, ainda que com diferentes tonalidades, quer nas grandes religiões, quer em diversas ideologias profanas. A Declaração Universal dos Direitos Humanos proclamada pela ONU em 1948, constitui sem dúvida uma outra aproximação doutrinária, ainda que a sua interpretação seja por vezes polémica e polissémica. (...) (O) exemplo e (o) magistério de algumas figuras que têm constituído autênticas vozes-âncora, combatendo objetivamente certas tendências relativistas e propondo caminhos de Paz. Só a título de exemplo bastará evocar as figuras universalmente reconhecidas de Gandhi, de Luther King, de Mandela, do Dalai-lama e do Papa Francisco (Carmo, 2016) (itálico meu).

No que respeita às fontes de natureza política, elas são várias, tanto oriundas do sistema das Nações Unidas como de estudos oficiais consagrados ${ }^{23}$. Como mera ilustração aponto as seguintes:

- os 17 Objetivos do Desenvolvimento Sustentável para o horizonte temporal de 2030, (ODS, 2030), legitimados em 2015 por 193 estados-membros da ONU, que constituem um excelente instrumento de orientação para a Paz;

- relatórios de estudos oficiais das nações unidas (e.g. Pintasilgo, 2017), ou encomendados por agências regionais como a União Europeia (e.g. Gnesotto \& Grevi 2008) ou de iniciativa estatal (Adler, 2009).

Retomando o rumo da reflexão, é minha convicção que, seguidamente, o Serviço Social, quer em contexto académico quer profissional, já dotado desta visão prospetiva, tem de olhar para o mapa para se orientar, revisitando as suas metas e os seus métodos.

\section{A questão das metas}

Em termos de metas, considerando os seus objetivos principais, parece-me importante abrir alguns trilhos para as explicitar melhor. Dou apenas dois exemplos: em primeiro lugar consciencializar que, quer a ajuda a populações carenciadas quer a promoção da participação não são fins últimos; em segundo que, para ser socialmente

\footnotetext{
${ }^{23}$ Felizmente, já lá vai o tempo em que os estudos prospetivos eram olhados com suspeição. Hoje, com a capacidade exponencial de computação e com o aumento significativo de estudos académicos sobre os sinais portadores de futuro, é possível selecionar fontes académicas credíveis. Propositadamente, dispenseime de dar exemplos, primeiro porque já há muitos de qualidade, são de fácil acesso e iria alargar excessivamente esta reflexão que tem constrangimentos editoriais.
} 
eficazes, exigem a prevenção de dois efeitos perversos: o assistencialismo e a alienação ideológica. Clarifiquemos:

Do meu ponto de vista, antes de mais, o fim último do serviço social tem de ter em conta que o fim último de qualquer sociedade é promover um estado de paz social e coletiva, considerando

(a paz pessoal como um) estado sustentável de bem-estar individual, decorrente da consciência dos direitos individuais garantidos e dos deveres cívicos cumpridos, o que pressupõe a satisfação das necessidades individuais de sobrevivência, de segurança, de sociabilidade, de autorrealização e de natureza existencial (...) (e a paz coletiva como um) estado de bem-estar social, decorrente da satisfação das necessidades sociais e políticas básicas, nomeadamente o sentimento de coesão social assente em alicerces de equidade e de justiça (...) e orientação para objetivos consensualmente valorizados (Carmo, 2016).

Daqui decorre que toda a ação a desenvolver, deve enquadrar-se nesse fim último, constituindo o principal critério de decisão profissional.

Por outro lado, a prevenção dos efeitos perversos dos processos de ajuda e de promoção da participação, envolve dois tipos de necessidades:

- a de qualificar o processo de ajuda, com vista a assumir que o (a) profissional de Serviço Social é um mero recurso ao serviço dos sistemas-clientes, procurando autonomizá-los e possibilitar-lhes o acesso ao poder de resolver os seus problemas. - a de qualificar a participação, desenvolvendo programas abrangentes de educação para a cidadania, tendo em consideração que a participação em si mesmo não é um valor: para o ser, tem de ser esclarecida ${ }^{24}$.

Estas reflexões têm dois corolários: em primeiro lugar obrigará as instituições formadoras e as (os) profissionais a associar mais vigorosamente à formação e à ação as dimensões, socioeducativa e sociopolítica. Em segundo, a revisitar o seu quadro de valores, nomeadamente o personalismo e a solidariedade, a fim poderem responder a novos dilemas éticos provocados pela mudança social e tecnológica.

A questão dos métodos e a formação das novas gerações de assistentes sociais

\footnotetext{
${ }^{24}$ A participação alienada promovida pela propaganda nazi, estalinista e, nos nossos dias, observada em países com regimes comummente designados populistas iliberais, é disso exemplo.
} 
No que respeita a métodos, parece haver necessidade de fazer três reaprendizagens: a discernir, a avaliar e a agir:

- reaprender a discernir com objetividade, dado o nevoeiro informacional envolvente, e dados os enviesamentos cognitivos e emocionais, empiricamente demonstrados por Rösling (2019), que muitas vezes obscurecem a observação dos problemas e deformam a sua interpretação;

- reaprender a avaliar, guiados por uma consciência mais afinada dos valores sociais nomeadamente o da paz, que integra, como referi atrás, as ideias de bemestar pessoal e coletivo dos seres humanos, e o de sustentabilidade, que, para além disso, envolve a relação harmoniosa com a nossa casa comum e os seus outros habitantes.

- reaprender a agir, às várias escalas de complexidade social (micro, meso, macro), motivado pelo compromisso cívico com o bem-comum, designado por responsabilidade social. Isto implicará, decerto, o aperfeiçoamento das técnicas de intervenção social clássicas (interpessoal, com grupos, com organizações, com comunidades e com redes), mas poderá envolver o desenvolvimento de outro tipo de competências (e.g. coaching, mediação, arbitragem, não violência ativa, audições públicas, comunicação online).

Nesta reaprendizagem do agir, é fundamental que tanto as instituições de formação (inicial e contínua, presencial e a distância) como os profissionais, tenham em conta que os problemas complexos serão cada vez mais frequentes e que, por isso, será necessário desenvolver individualmente as inteligências-bússola e, coletivamente a governação integrada, de modo que a metodologia de intervenção seja assente em duas dinâmicas:

O movimento de acumulação -sistematização pragmática, onde o assistente social age pela acumulação de experiências e a postura reflexiva face ao impacto das suas práticas num determinado contexto (e o de) investigação-sistematização científica, que alia os procedimentos de pesquisa formal ao processo de reflexividade empírica (...) (Santos, 2014, p.94). 


\section{Concluindo}

A melhor maneira de terminar esta reflexão é recordar o que Lena Dominelli afirmou, a propósito da pandemia, no prefácio a uma obra recente atrás referida (Carvalho, 2020):

As comunidades tornaram-se a base do apoio social, reforçando o seu papel como local de apoio, e os assistentes sociais foram os elos de ligação entre elas. Isto deixa-nos com um legado para construir um novo futuro. Um futuro baseado na solidariedade, na autoajuda mútua, cuidando uns dos outros e, acima de tudo, cuidando da Mãe Terra (...). Somente vinculando a humanidade, o meio ambiente e a sociedade de forma sustentável, os assistentes sociais podem mitigar o risco dos desastres que nos assolam a todos (...) (itálico meu).

Para que tal seja possível, teremos de reformar a formação e os modelos de intervenção no Serviço Social. Primeiramente, há que cuidar dos próprios profissionais, formando-os para o autocuidado, dando mais atenção ao desenvolvimento das suas inteligências bússola ${ }^{25}$ e criando condições de supervisão. Em segundo lugar, haverá que qualificar os (as) profissionais não só no cuidado individual, mas também no cuidado coletivo. E, para isso, será necessário dar mais importância às dimensões socioeducativa e sociopolítica na prática profissional. E, tudo isto, ao serviço da construção da Paz.

\section{Referências bibliográficas}

Adler, A. (2009). O novo relatório da CIA: como será o mundo em 2025? Bizâncio.

Ander-Egg, E. (1984). El desafio de la reconceptualization. Hvmanitas.

Bauman, Z. (2016). Cegueira moral: a perda de sensibilidade na modernidade líquida. Relógio d’Água.

Cardoso, J., Vilar, D., Casquilho-Martins (2020). Desafios ao serviço social no contexto da COVID-19. CLISSIS

Carmo, H. (1999). Desenvolvimento comunitário (1ª edição). Universidade Aberta.

Carmo, H. (2010). Virtualidades e limitações do e-learning: o caso da Universidade Aberta. In Mill, D. \& Pimentel, N. Educação a distância: desafios contemporâneos (pp.139-162). EdUFSCar.

Carmo, H. (2011). Teoria da política social: um olhar da Ciência Política. ISCSP

\footnotetext{
${ }^{25}$ Sobre isto vejam-se, por exemplo, os trabalhos recentes de Duarte (2018) e de Teles (2017)
} 
Carmo, H. (2014a). Educação para a cidadania no século XXI: trilhos de intervenção. Escolar Editora

Carmo, H. (2014b). Educação para a cidadania: um imperativo estratégico para o serviço social. In Carvalho, M.I. \& Pinto, C. (eds.). Serviço Social: Teorias, e práticas (pp.113-128). PACTOR.

Carmo, H. (2016). A paz e a cidadania global no contexto de uma estratégia de educação para a cidadania. In Simpósio Internacional de educação e pedagogia sobre Paz e cidadania global. UAb

Carmo, H. (2018). A importância da inteligência emocional nas profissões ligadas à intervenção social. In "Mais Social". LNSS.ISCSP.

Carmo H. \& Carmo, T. M. (2018). Valor dos MOOC na educação para a cidadania. In Pimentel, N. (eds.). Tecnologias educacionais e EaD, "Inclusão Social" (Número temático). http://revista.ibict.br/inclusao/issue/view/242.

Carmo, H. (2020). Efeitos da pandemia Covid 19 na educação para a cidadania, In Reflexões sobre Psicologia e Educação no contexto da pandemia no Brasil e em Portugal, Editora brasileira da Universidade Federal do Piauí/UFPI - EDUFPI, no prelo.

Carvalho, M. I. \& Pinto, C. (2014). Serviço Social: Teorias, e práticas. PACTOR.

Carvalho, M. I. (2020) (Coord.). Serviço social em catástrofes. PACTOR.

CES - Conselho Económico e Social (2020). COVID 19: Sair da crise - Emprego, apoios sociais e saúde. Editorial do Ministério da Educação e Ciência.

CNDH - Comissão Nacional para os Direitos Humanos (2020). Portugal e a promoção e proteção dos direitos humanos. $\mathrm{CNDH}$.

Duarte, C. (2018). Inteligência emocional e inteligência espiritual: Contributos para a humanização do Serviço Social numa sociedade em mudança. ISCSP/UL. Tese de doutoramento.

Esgaio, O. A. (2018) A responsabilidade social e a redescoberta da solidariedade: representações e práticas de responsabilidade social no serviço social. ISCSP/UL. Tese de doutoramento.

Falcão, M. C. (1979). Uma nova visão teórica do serviço social. Cortez \& Moraes.

Ferguson, N. (2018). A praça e a torre: redes, hierarquias e a luta pelo poder global. Temas e Debates e Círculo do Leitor.

Francisco (2020). Fratelli Tutti: Carta Encíclica sobre a fraternidade e a amizade social. Paulinas.

Freire, P. (1972). Pedagogia do Oprimido. Afrontamento.

Fukuyama, F. (2000). A grande rutura: a natureza humana e a reconstituição da ordem social. Quetzal.

Gardner, H. (1995). Inteligências múltiplas: a teoria e a prática. Artes Médicas.

GEIES - Grupo Estatal de Intervención en Emergencias Sociales (2020). Recomendaciones del Consejo General del Trabajo Social para los Sevicios Sociales ante la situación del COVID 19 y la post crisis. Consejo General del Trabajo Social.

GEIES - Grupo Estatal de Intervención en Emergencias Sociales (2020). El duelo por el COVID 19 desde el Trabajo Social. Consejo General del Trabajo Social. 
Gnesotto, N. \& Grevi, G. (2008). O mundo em 2025 segundo os especialistas da União Europeia. Bizâncio.

Goleman, D. (2006). Inteligência social. Temas e Debates

Granja, B. (2014). Contributos para a análise das formas identitárias dos assistentes sociais. In Carvalho, M. I. \& Pinto, C. (coords.). Serviço Social: Teorias, e práticas (pp.27-56). PACTOR.

Johson, S. (2010). As ideias que mudaram o mundo: a história natural da inovação. As estratégias para cultivar as nossas futuras descobertas criativas. Clube do Leitor.

Laurent, E. (2020). De olhos postos no amanhã: valorizar o bem-estar, a resiliência e a sustentabilidade no século XXI. Casa das Letras. Govint.

Marques, R. (2017). Problemas sociais complexos e Governação Integrada.

Morin, E. (1991). Os problemas do fim do século. Notícias.

Mouro, H. (2014). Teoria e teorizar em serviço social. In Carvalho, M.I. \& Pinto, C. (cords.). Serviço Social: Teorias, e práticas (pp.57-86). PACTOR.

Paul, Brun \& Taylor (2020). Recasting social workers as frontline in a socially accountable COVID-19 response. SAGE document digital.

Peccei, A. (1981). Cem páginas para o Futuro. Universidade de Brasília.

Piketty, T. (2020). Capital e ideologia. Círculo de Leitores.

Pintasilgo, M.L., (2017). Cuidar o Futuro: um programa radical para viver melhor. Relatório da Comissão Independente População e Qualidade de Vida. Fundação Cuidar o Futuro.

Pinto, C. (2012). Representações e práticas do empowerment nos trabalhadores sociais. ISCSP.

Reigada, C., (2020) (coord.). Boas Práticas do Assistente Social COVID-19. https://drive.google.com/file/d/1ZMw0_KaeaDf2fkVOgLhS4p5gsAOwWgc5/view

Ribeirinho, C. (2019). Supervisão profissional em serviço social. PACTOR.

Rosnay, J. de (1977). O Macroscópio: para uma visão global. Arcádia.

Santos, C. (2014). A identidade profissional do serviço social: uma análise reflexiva. In Carvalho, M.I. \& Pinto, C. (coords.). Serviço Social: Teorias, e práticas (pp.57-86). PACTOR.

Rosling, H. \& Rosling, A. (2019). Factfullness (Factualidade): 10 razões pelas quais estamos errados acerca do mundo-e porque as coisas estão melhor do que pensamos. Bertrand.

Stiglitz, J.E. (2013). O Preço da Desigualdade. Bertrand.

Stiglitz, J.E. (2018) O Fim da Desigualdade. Bertrand.

Strenger, C. (2012). O medo da insignificância como dar sentido às nossas vidas no século XXI. Lua de Papel.

Taleb, N. (2016). O cisne negro ( $8^{\mathrm{a}} \mathrm{ed}$.). D. Quixote.

Teles, H. (2017). Serviço social e responsabilidade social empresarial interna: os desafios contemporâneos dos assistentes sociais. Lisboa: ISCSP. Tese de doutoramento. 
Toffler, A. (1970), Choque do futuro. Livros do Brasil.

Toffler, A. (1980). A terceira vaga. Livros do Brasil.

Toffler, A. (1991). Os Novos Poderes. Livros do Brasil.

Toffler, A. \& Toffler, H. (2006). A revolução da riqueza. Actual.

VVAA (2020). Relatório final: SM-COVID19) Saúde mental em tempos de pandemia. Instituto Nacional de Saúde Dr. Ricardo Jorge. Instituto de Saúde Ambiental da Faculdade de Medicina da Universidade de Lisboa. Sociedade Portuguesa de Psiquiatria e Saúde Mental. 